\title{
Heat transfer enhancement with gas-to-gas micro heat exchangers
}

\author{
Iris GERKEN ${ }^{1, *}$, Juergen J. BRANDNER ${ }^{1}$, Roland DITTMEYER ${ }^{1}$ \\ *Corresponding author: Tel.: ++49 (0)721 60824094; Fax: ++49 (0)721 60823186; \\ Email: iris.gerken@kit.edu \\ 1 Institute for Micro Process Engineering (IMVT), Karlsruhe Institute of Technology (KIT), Germany
}

\begin{abstract}
A characterization of gas-to-gas micro heat exchangers has been performed in terms of pressure drop behavior and heat transfer performance. The gas-to-gas micro heat exchangers differ by partition wall material, partition wall thickness and flow arrangement. The pressure drop behavior has been analyzed due to the pressure losses in different sections of the gas-to-gas micro heat exchangers. Increased pressure losses in front of and behind the micro channels have been detected due to modified geometries in the inlet and outlet distribution chambers. The heat transfer performance has been determined in terms of thermal effectiveness. The comparison among different partition wall materials and partition wall thicknesses showed no significant criteria of the influence of thermal conductivity on the thermal effectiveness. An assessment due to an overall heat exchanger effectiveness has been performed to compare the gas-to-gas micro heat exchangers. For this purpose, the overall exergy loss has been calculated by combination of thermal effectiveness and pressure losses. A strong impact of the exergy loss due to pressure drop has been detected which influences the overall exergy loss of the gas-to-gas micro heat exchangers.
\end{abstract}

Keywords: Heat transfer enhancement, Heat exchanger, Energy efficiency, Gas heat transfer

\section{Introduction}

Heat transfer in micro heat exchangers has been proven to be superior compared to conventional devices due to higher surface-tovolume ratios and very short heat transfer distances. The small channel dimensions of less than $10^{-3} \mathrm{~m}$ lead to increased pressure losses considering micro scale flow channels. For heat transfer enhancement of micro heat exchangers, the micro channels normally used can be replaced with modified geometries, e.g. pin fins, different channel flow paths or channel sectional areas (Brandner et al., 2006; Mohammed et al., 2011; Wu and Cheng, 2003). A disadvantage of such structures is additional pressure loss. An overall assessment to consider both, heat transfer performance and pressure drop behavior needs to be performed to compare heat exchangers with an energy efficiency method.

Besides the comparison of an augmented surface to a smooth surface, performed by e.g. Webb and Kim (Webb and Kim, 1994) and Bejan (Bejan, 1987), there are possibilities to compare between two augmented surfaces.
The second law of thermodynamics has been used by several authors (Bejan, 1987; Tandogan, 2001; $\mathrm{Wu}$ and $\mathrm{Li}, 2001$ ) for different approaches, namely due to entropy generation or exergy loss.

In the following, the theoretical background to calculate the overall exergy loss which is the sum of the exergy loss due to heat transfer and the exergy loss appearing due to pressure loss is presented. The experimental method introduces a flexible gas-to-gas micro heat exchanger which provides the option to investigate different partition wall materials, partition wall thicknesses and flow arrangements. The results are separated considering pressure drop behavior, heat transfer performance and the overall heat exchanger effectiveness.

\subsection{Theoretical background}

The second law of thermodynamics describes irreversibility, which appears during a process, e.g. due to heat and mass transfer. Irreversibility means the process cannot be converted to its initial conditions without 
additional energy. Process entropy describes this irreversibility. Although the entropy in a thermodynamic process can only be increased or decreased, published literature refers to the entropy changes as "entropy generation" or "entropy production". In the following this nomenclature is retained.

Irreversibility resulting from heat transfer and fluid flow during heat transfer processes lead to a loss of exergy due to an increase of anergy. Exergy is the content of energy which can be changed into work whereas the contrary content of energy is anergy. Therefore, entropy generation is always connected to a loss of exergy. To compare heat exchangers, the overall exergy loss can be calculated. A lower overall exergy loss then reveals a more efficient overall heat exchanger.

The method to calculate the overall exergy loss $(\Delta E)$ has been previously published by $\mathrm{Wu}$ and $\mathrm{Li}(\mathrm{Wu}$ and $\mathrm{Li}, 2001)$. The overall exergy loss $(\Delta E)$ can be calculated with the following equation (1) due to exergy loss in terms of heat transfer $\left(\Delta E_{T}\right)$ and exergy loss due to pressure drop $\left(\Delta E_{P}\right)$ :

$$
\Delta E=\Delta E_{T}+\Delta E_{P}
$$

The exergy loss in consequence of heat transfer $\left(\Delta E_{T}\right)$ can be calculated as follows:

$$
\begin{aligned}
\Delta E_{T}= & \dot{M}_{H} \cdot c_{P, H} \cdot T_{O} \cdot(\ln (1-\varepsilon \cdot R \cdot(1-c)) \\
& \left.+R \cdot \ln \left(1+\varepsilon\left(\frac{1}{c}-1\right)\right)\right)
\end{aligned}
$$

with $\dot{M}_{H}$ and $c_{P, H}$ as mass flow rate and specific heat capacity of the hot fluid flow and $T_{0}$ as ambient temperature. The thermal effectiveness $(\varepsilon)$, the temperature ratio $(c)$ and the ratio of heat capacity rates $(R)$ are defined as follows:

$$
\begin{gathered}
\varepsilon=\frac{\dot{M}_{C} \cdot c_{P, C} \cdot\left(T_{C, \text { out }}-T_{C, \text { in }}\right)}{\left(\dot{M} \cdot c_{P}\right)_{\min } \cdot\left(T_{H, \text { in }}-T_{C, \text { in }}\right)} \\
=\frac{\dot{M_{H}} \cdot c_{P, H} \cdot\left(T_{H, \text { out }}-T_{H, \text { in }}\right)}{\left(\dot{M} \cdot c_{P}\right)_{\min } \cdot\left(T_{H, \text { in }}-T_{C, \text { in }}\right)}
\end{gathered}
$$

and

$$
c=\frac{T_{C, i n}}{T_{H, i n}}
$$

and

$$
R=\frac{\dot{M}_{C} \cdot c_{P, C}}{\dot{M}_{H} \cdot c_{P, H}}
$$

with the temperature $(T)$ at the inlet (in) or outlet (out) for hot $(H)$ or cold $(C)$ fluid flow.

The exergy loss due to pressure drop $\left(\Delta E_{P}\right)$ is calculated depending on the test fluid. Assuming a perfect gas it is calculated as follows:

$$
\begin{gathered}
\Delta E_{P}=-T_{0}\left(\dot{M}_{H} \cdot R_{g a s} \cdot \ln \left(1-\frac{\Delta p_{H}}{p_{H, \text { in }}}\right)\right. \\
\left.+\dot{M}_{C} \cdot R_{\text {gas }} \cdot \ln \left(1-\frac{\Delta p_{C}}{p_{C, \text { in }}}\right)\right)
\end{gathered}
$$

with $\dot{M}$ as mass flow rate, $\Delta p$ as pressure loss and $p$ as pressure. $R_{\text {gas }}$ refers to the specific gas constant of the gas flow. The subscripts $H$ and $C$ refer to the hot and cold fluid flow. The subscript in refers to the inlet of the heat exchanger.

Considering the test fluid to be an incompressible liquid with the specific volume (v) to be constant, the exergy loss due to pressure drop is calculated as follows:

$$
\Delta E_{P}=\dot{M}_{H} \cdot v_{H} \cdot \Delta p_{H}+\dot{M}_{C} \cdot v_{C} \cdot \Delta p_{C}
$$

This method is used to augment gas-to-gas micro heat exchangers. Therefore, equation (6) is used to determine the exergy loss due to pressure drop for gas as test fluid. As has been shown, heat transfer in gas-to-gas micro heat exchangers has been scarcely experimentally investigated. Yang et al. (Yang et al., 2012a) summarized the existing literature references. The literature references assume isothermal behavior due to strong longitudinal conduction along the solid walls (Bier et al., 1993; Kee et al., 2011; Koyama and Asako, 2010a, b; Meschke et al., 2005). The influence of longitudinal conduction has been previously investigated by Yang et al. (Yang et al., 2012b). 
An experimental device developed by Yang et al. (Yang et al., 2012b) has been used to investigate the effects of different partition wall materials, partition wall thicknesses and flow arrangements leading to different gas-togas micro heat exchangers. To illustrate the influence on the assessment of heat exchangers, results of pressure drop behavior and heat transfer performance presented by Yang et al. (Yang et al., 2012b) are summarized in the following. The assessment has been performed in terms of the overall exergy loss with the above mentioned method (see equation 7).

\section{Experimental method}

The experimental test setup is shown in Fig. 1. A compressor generates a high pressure air flow at room temperature which is firstly filtered by a sintered metal cartridge filter (Swagelok). After the filter, the flow is split into two branches which are proposed to supply the gas-to-gas micro heat exchanger as hot and cold flows. The flow rate of each branch is controlled by a MFC (Brooks, SLA5851), and the temperature is adjusted by a temperature regulator. In front of and behind the gas-to-gas micro heat exchanger, temperature (Conatex, $\mathrm{K}$ type tc) and pressure (Wika) of each flow branch are measured. The exiting gas is vented to the atmosphere.

The uncertainties of the sensors are listed in Table 1. The total uncertainty of the thermal effectiveness has been estimated to be between $1.0 \%$ and $3.6 \%$ for the uncertainties and measured values of the parameters used for the current study.

Table 1 Uncertainties of measurement methods.

\begin{tabular}{l|l}
\hline Measurement & Uncertainty \\
\hline Pressure (Wika) & $\pm 0.5 \%$ \\
Temperature & $\pm 0.5 \%$ \\
(Conatex, & \\
K Type tc) & \\
Mass flow rate & $\pm 1 \%$ of measured value \\
(Brooks) & $(20 \%$ F.S. $<\dot{M}>$ F.S. \\
& $\pm 0.2 \%$ of F.S. \\
& $\dot{M}<20 \%)$ \\
\hline
\end{tabular}

The gas-to-gas micro heat exchanger is presented in Fig. 2 a) as an exploded view CAD drawing. The core of the device consists

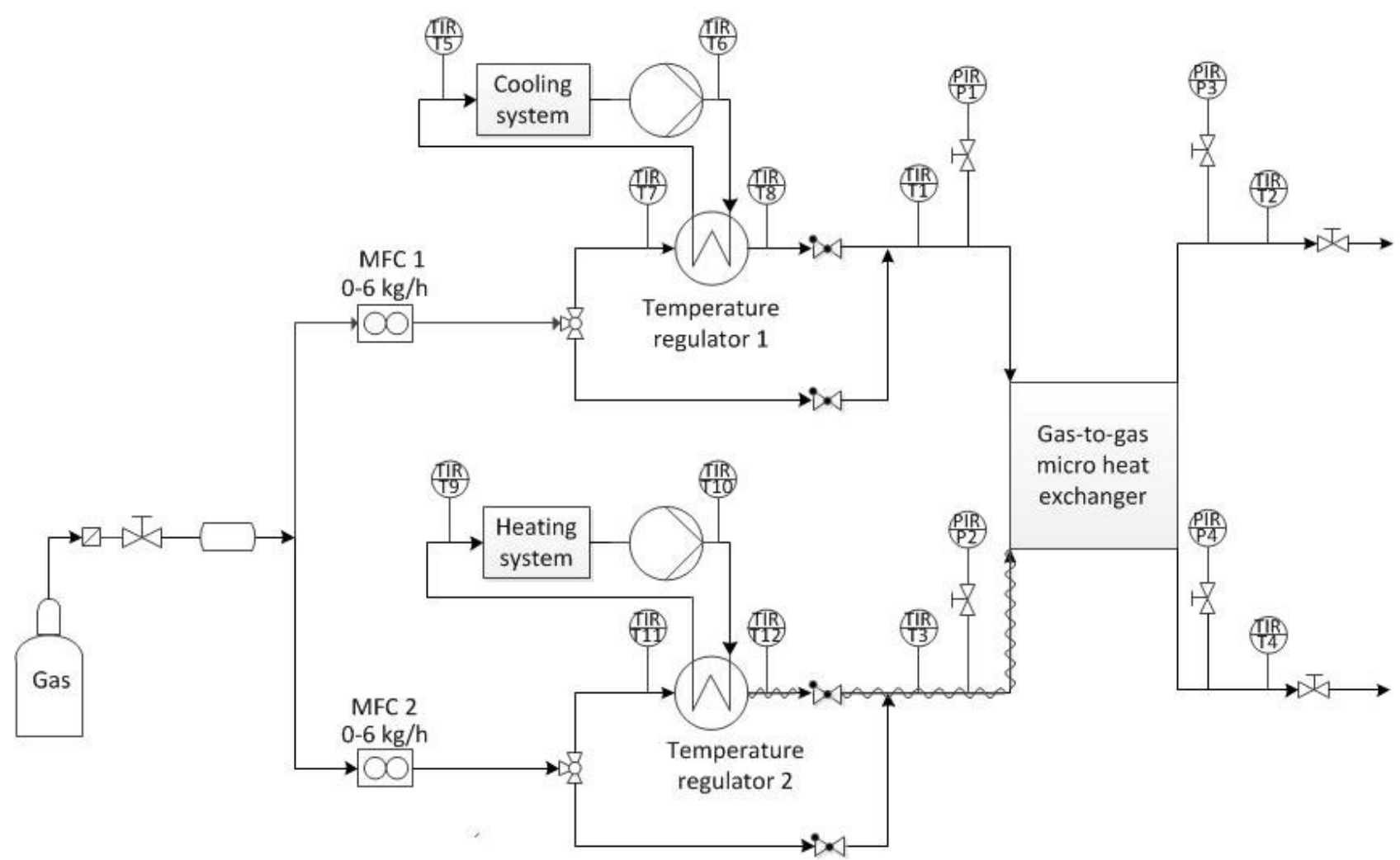

Fig. 1 Schematic view of the experimental setup. 
of two PEEK foils with micro channels (5) which are divided by an exchangeable partition foil (6). Screws assemble the micro channel test section to a cover and bottom which are made of stainless steel (4). The cover and bottom enable access to conventional pipe connections for gas inlet (3) and gas outlet (7) and offer the possiblity of measuring temperature (1) and pressure (2) inside the gas-to-gas micro heat exchanger.

For use of the gas-to-gas micro heat exchanger as co current or counter current device, the pipes connected to the cover and bottom have to be exchanged depending on the gas flow arrangement. In case of a cross flow arrangement one of the PEEK micro channel foils is rotated by $90^{\circ}$.

Fig. 2 b) shows the PEEK foil with the micro channels and the inlet and outlet distribution chambers. It consists of 133 parallel micro channels with a channel width and height of $W=H=20010^{-6} \mathrm{~m}$ each and a length of $L=39.810^{-3} \mathrm{~m}$. Therefore, a hydraulic diameter of $d_{h}=20010^{-6} \mathrm{~m}$ can be determined. Fig. 2 c) shows a zoom into the inlet distribution chamber. Additional temperature and pressure sensors have been placed directly in front of the micro channels. In addition, pillars are integrated in the inlet distribution chamber to maintain mechanical stability. Similar arrangement of sensors and pillars can be found in the outlet distribution chamber.

The gas-to-gas micro heat exchanger has been operated with balanced mass flow rates up to $\dot{M}=2.25 \mathrm{~kg} / \mathrm{h}$. For the experiments, different partition foil materials and thicknesses have been tested. Table 2 lists the materials, the thermal conductivity and the thickness.

Table 2 Partition foil material, thermal conductivity and thickness.

\begin{tabular}{l|l|r|r}
\hline Case & Material & $\begin{array}{l}\text { Thermal } \\
\text { conductivity } \\
(\mathrm{W} / \mathrm{m} / \mathrm{K})\end{array}$ & $\begin{array}{l}\text { Thickness } \\
\left(10^{-6} \cdot \mathrm{m}\right)\end{array}$ \\
\hline 1 & PEEK & 0.25 & 500 \\
2 & Stainless & 16.30 & 100 \\
& steel & 148.00 & 100 \\
3 & Aluminum & 401.00 & 100 \\
4 & Copper & 401.00 & 500 \\
5 & Copper & \\
\hline
\end{tabular}
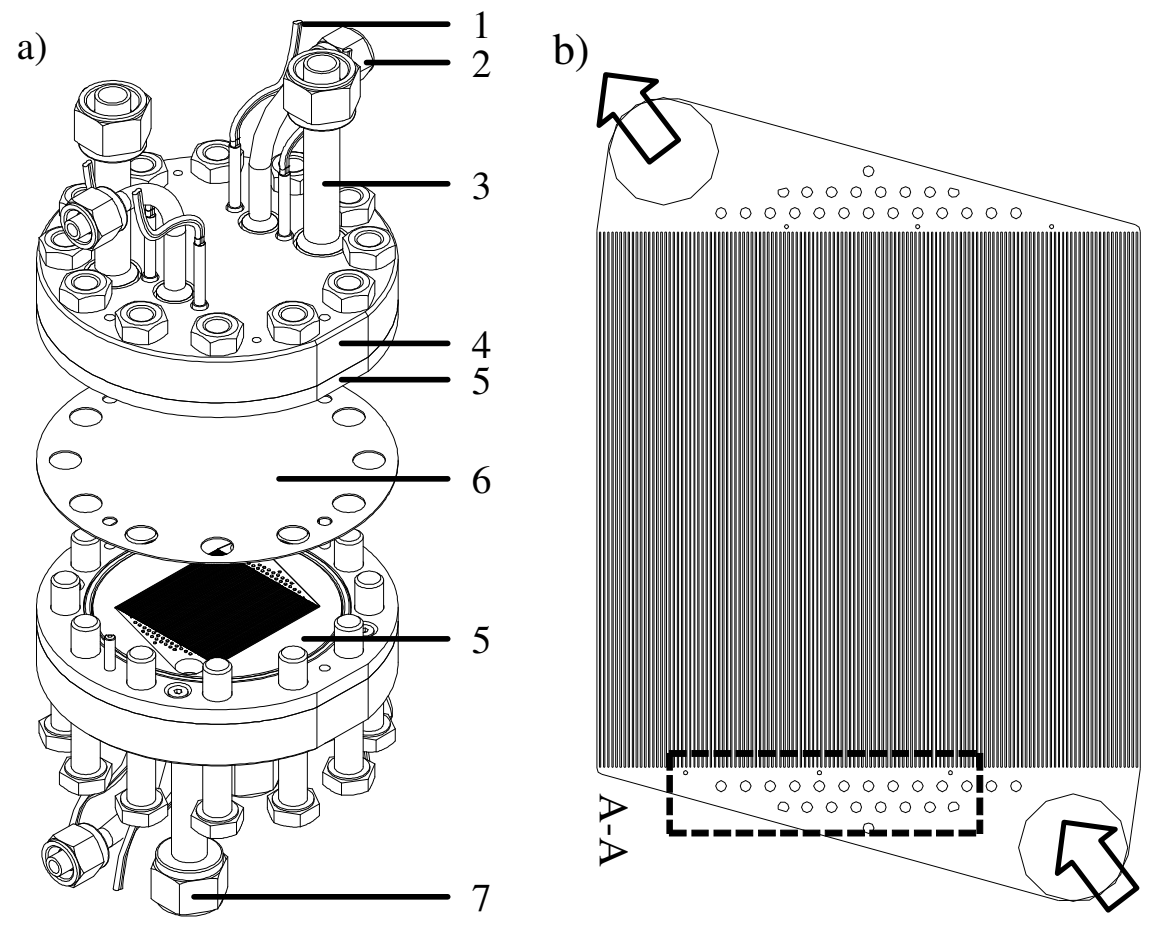

c)

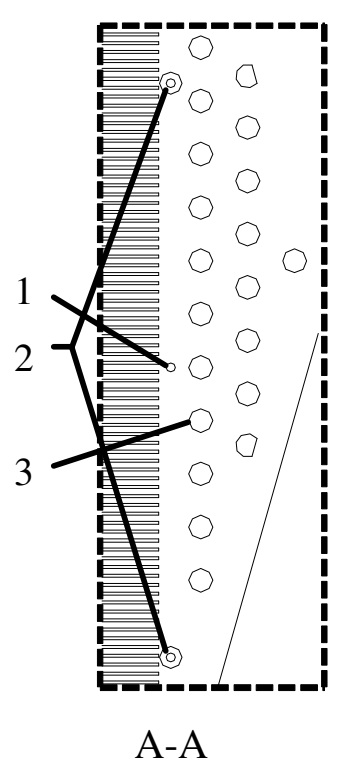

Fig. 2 a) Exploded view CAD drawing of the gas-to-gas micro heat exchanger: (1) temperature sensors, (2) pressure sensors, (3) gas inlet, (4) stainless steel cover, (5) PEEK foil with micro channels, (6) partition foil made of PEEK, exchangeable against other materials, (7) gas outlet. b) PEEK foil with 133 micro channels and c) position of measurement sensors from Yang et al. (Yang et al., 2012b): access for pressure measurements, (2) thermocouples, (3) pillars. 


\section{Results and discussion}

\subsection{Pressure drop behavior}

The pressure drop behavior has been analyzed due to the pressure losses in different sections of the gas-to-gas micro heat exchanger. The pressure drop behavior is independent of material, i.e. surface roughness, and flow arrangement, thus, the results are here only presented for a stainless steel partition foil and counter current flow arrangement.

The pressure has been measured in front of and behind the device as well as directly in front of and behind the micro channels. Therefore, the pressure losses in the inlet distribution chamber, in the outlet distribution chamber and along the micro channels can be calculated and compared to each other. Fig. 3 summarizes the results for different mass flow rates.

It can be noticed that, with increasing mass flow rate, the pressure losses in all sections increase. In comparison to the pressure loss along the micro channels, much higher pressure losses have been detected in the inlet distribution chamber and in the outlet distribution chamber. This appears to be due to the presence of pillars in the inlet and outlet distribution chambers which leads to an increased friction, most likely by changing the flow mode. However, the pillars could not be avoided for mechanical stability reasons.

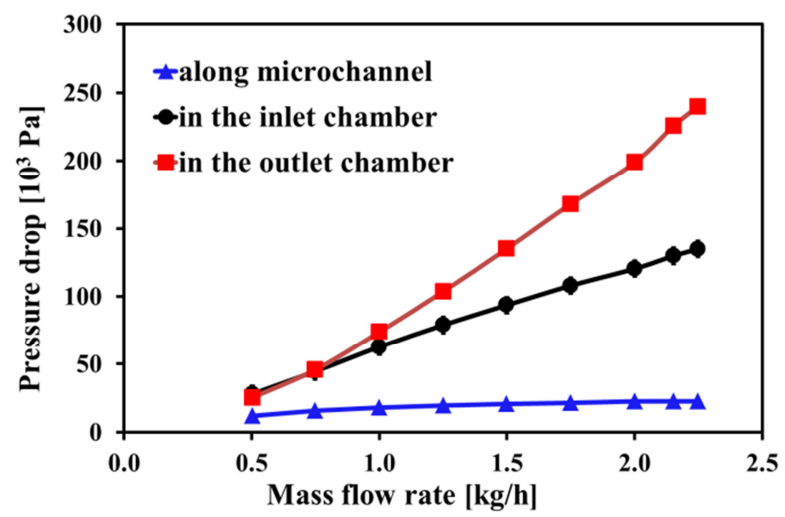

Fig. 3 Pressure drop along the micro channels, in the inlet distribution chamber and the outlet distribution chamber for a stainless steel partition foil and counter current flow arrangement.

\subsection{Heat transfer performance}

The heat transfer performance has been analyzed with the thermal effectiveness calculated by equation (3). The influence of flow arrangement on different partition foil materials and partition foil thicknesses is similar to each other. Therefore, the thermal effectiveness is demonstrated for a stainless steel partition foil with a partition foil thickness of $\delta=100 \cdot 10^{-6} \mathrm{~m}$.

The results presented in Fig.4 show that the thermal effectiveness for each flow arrangement decreases with increasing mass flow rate. In addition, the thermal effectiveness of the counter current device exceeds that of the cross flow heat exchanger and the co current flow device, which is a well-known behavior.

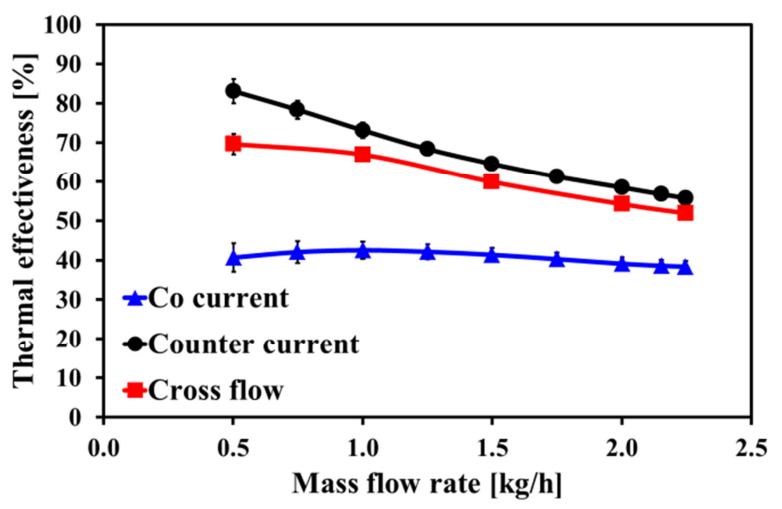

Fig. 4 Thermal effectiveness of a stainless steel partition foil with a thickness of $\delta=100 \cdot 10^{-6} \cdot \mathrm{m}$ for different flow arrangements.

A comparison among different partition foil materials and thicknesses is shown in Fig. 5 for counter current flow arrangement. Again, the thermal effectiveness decreases with increasing mass flow rate. The results for aluminum, stainless steel and copper with a partition foil thickness of $\delta=100 \cdot 10^{-6} \mathrm{~m}$ reveal an overlapping trend, although different thermal conductivities are compared. With increasing partition foil thickness of $\delta=500 \cdot 10^{-6} \mathrm{~m}$ for PEEK and copper, the thermal effectiveness decreases. 


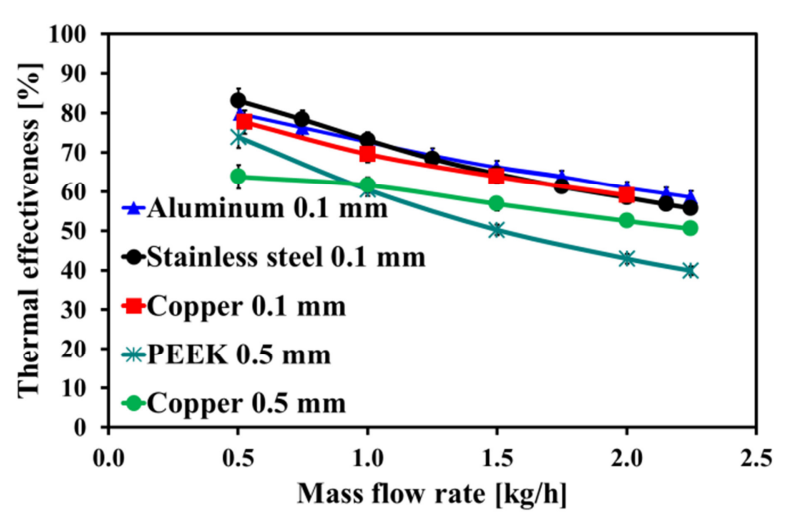

Fig. 5 Thermal effectiveness of different partition foil materials and partition foil thickness and counter current flow arrangement.

Results of the heat transfer performance reveal no isothermal behavior of the different gas-togas micro heat exchangers. However, a significant impact of different materials onto the thermal effectiveness due to their thermal conductivity cannot be detected.

\subsection{Overall heat exchanger effectiveness}

For the assessment of an overall heat transfer effectiveness the exergy loss has been calculated with the temperature and pressure measurement results in front of and behind the gas-to-gas micro heat exchanger to reveal the performance of the entire device. The exergy losses have been analyzed for different partition foil materials and partition foil thicknesses and counter current flow arrangement.

Fig. 6 demonstrates the exergy losses in terms of pressure drop and heat transfer. For both cases, the exergy loss increases with increasing mass flow rate.

The exergy losses due to pressure drop deviate for partition foils made of aluminum and copper, both with partition foil thicknesses of $\delta=100 \cdot 10^{-6} \cdot \mathrm{m}$. This appears to be due to mechanical instability in terms of deformation of the partition foil, which could be detected in the inlet and outlet distribution chambers.

The results of the exergy loss due to heat transfer demonstrate increased exergy loss for a partition foil made of copper and $\delta=500 \cdot 10^{-6} \mathrm{~m}$ partition foil thickness. In the case of the other materials overlapping trends can be observed.

In comparison, a maximum exergy loss in terms of pressure drop of $\Delta E_{P}=220 \mathrm{~W}$ has been detected for an aluminum foil with a partition foil thickness of $\delta=100 \cdot 10^{-6} \mathrm{~m}$, whereas a maximum exergy loss in terms of heat transfer of $\Delta E_{T}=2.57 \mathrm{~W}$ for a copper foil with a partition foil thickness of $\delta=500 \cdot 10^{-6} \mathrm{~m}$ has been discovered.

This behavior can be proved by analyzing the overall exergy loss, which is shown in Fig. 7. The same trend of the plots can be observed comparing with the exergy loss due to pressure drop (Fig. 6). Therefore, the exergy loss in terms of pressure drop exceeds the exergy loss in terms of heat transfer.
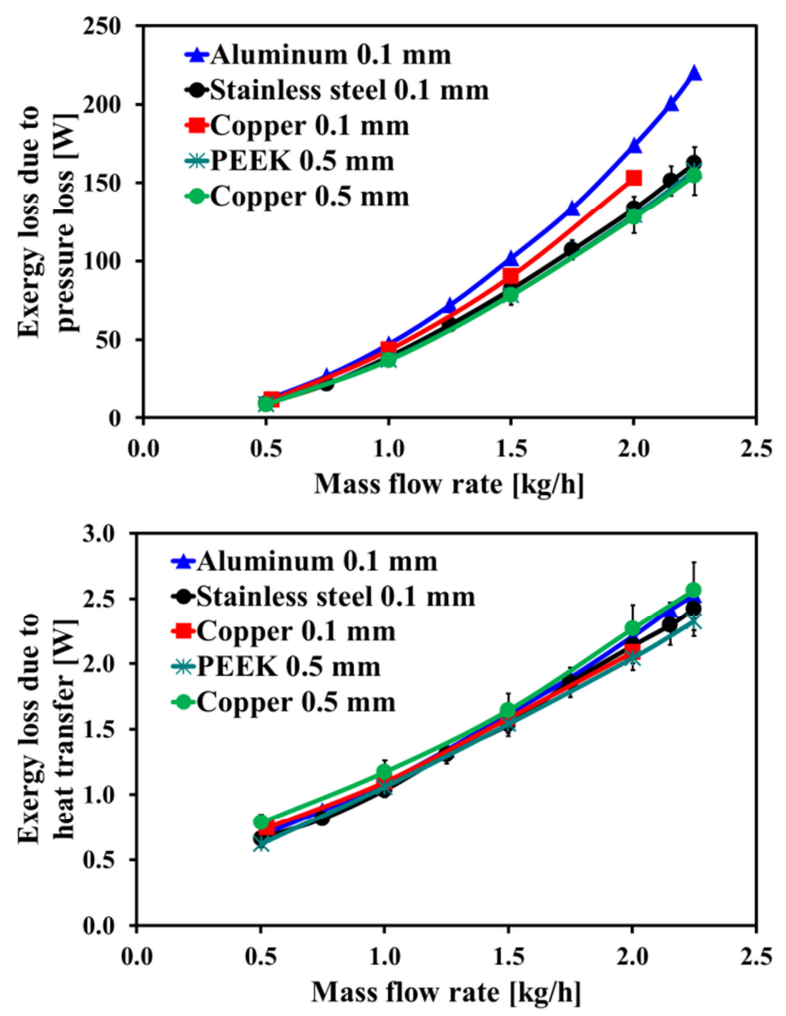

Fig. 6 Exergy loss due to pressure drop and exergy loss due to heat transfer for different partition foil materials and counter current flow arrangement. 


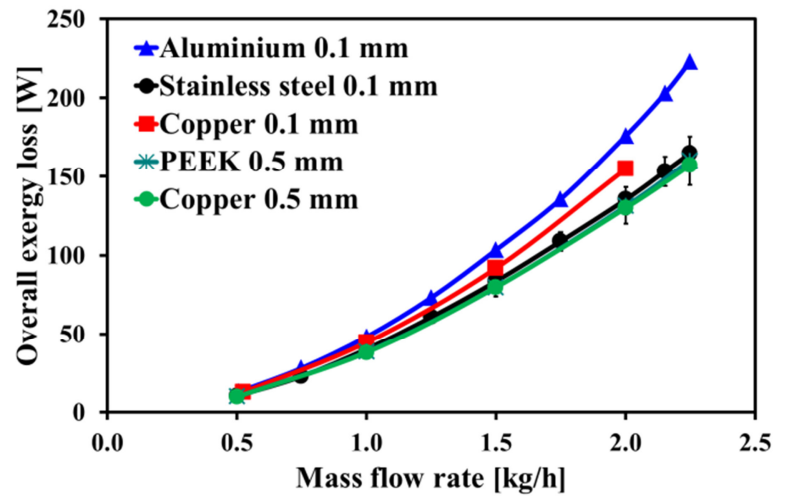

Fig. 7 Overall exergy loss for different partition foil materials and counter current flow arrangement.

In conclusion, the influence of pressure drop behavior to the overall heat exchanger effectiveness exceeds the impact of the heat transfer performance by far. An optimization of gas-to-gas micro heat exchangers is required to decrease the pressure losses, after this the increase of the heat transfer performance can take place.

\section{Summary and conclusion}

A gas-to-gas micro heat exchanger has been studied in terms of pressure drop behavior and heat transfer performance for different partition foil materials, partition foil thicknesses and flow arrangements. An assessment of different gas-to-gas micro heat exchangers has been performed in terms of exergy losses.

Pressure drop behavior has been analyzed by measurement of pressure losses in different sections. Increased pressure losses have been detected at the inlet and outlet of the micro channels due to modified entrance and exit geometries in the inlet and outlet distribution chamber.

The heat transfer performance has been analyzed by comparing the thermal effectiveness of different flow arrangements, partition foil materials and partition foil thickness. Although materials with different thermal conductivities have been used, no significant influence on the thermal effectiveness has been detected.

Finally, the overall heat exchanger effectiveness has been investigated to assess different gas-to-gas micro heat exchangers in terms of exergy losses due to pressure drop and heat transfer. The results show an increased exergy loss by pressure drop behavior compared to the exergy loss by heat transfer performance. Therefore, the gas-to-gas micro heat exchangers need to be modified to increase the impact of heat transfer performance and to decrease the influence of pressure drop behavior.

\section{Acknowledgement}

The authors would like to thank the microfabrication group at IMVT, Karlsruhe Institute of Technology (KIT), for manufacturing and assembling of the gas-togas micro heat exchangers.

\section{Nomenclature}

$\begin{array}{lll}c & \text { temperature ratio } & (-) \\ c_{P} & \text { specific heat capacity } & (\mathrm{J} / \mathrm{kg} \mathrm{K}) \\ d_{h} & \text { hydraulic diameter } & (\mathrm{m}) \\ \Delta E & \text { exergy loss } & (\mathrm{W}) \\ \Delta E_{T} & \text { exergy loss due to heat transfer } & (\mathrm{W}) \\ \Delta E_{P} & \text { exergy loss due to fluid flow } & (\mathrm{W}) \\ H & \text { height } & (\mathrm{m}) \\ L & \text { length } & (\mathrm{m}) \\ \dot{M} & \text { mass flow rate } & (\mathrm{kg} / \mathrm{s}) \\ p & \text { pressure } & (\mathrm{Pa}) \\ \Delta p & \text { pressure loss } & (\mathrm{Pa}) \\ R & \text { ratio of heat capacity rates } & (-) \\ R_{\text {gas }} & \text { specific gas constant } & (\mathrm{J} / \mathrm{kg} \mathrm{K}) \\ T & \text { temperature } & (\mathrm{K}) \\ t c & \text { thermocouple } & (-) \\ W & \text { width } & (\mathrm{m}) \\ \varepsilon & \text { thermal effectiveness } & (-) \\ v & \text { specific volume } & \left(\mathrm{m}^{3} / \mathrm{kg}\right)\end{array}$

Subscripts

0 ambient

$C$ cold fluid flow

$H$ hot fluid flow

in inlet

min minimum

out outlet 


\section{References}

Bejan, A., 1987. The thermodynamic design of heat and mass transfer processes and devices. International Journal of Heat and Fluid Flow 8, 258-276.

Bier, W., Keller, W., Linder, G., Seidel, D., Schubert, K., Martin, H., 1993. Gas to gas heat transfer in micro heat exchangers. Chemical Engineering and Processing: Process Intensification 32, 33-43.

Brandner, J.J., Anurjew, E., Bohn, L., Hansjosten, E., Henning, T., Schygulla, U., Wenka, A., Schubert, K., 2006. Concepts and realization of microstructure heat exchangers for enhanced heat transfer. International Journal of Experimental Thermal and Fluid Science 30, 801-809.

Kee, R.J., Almand, B.B., Blasi, J.M., Rosen, B.L., Hartmann, M., Sullivan, N.P., Zhu, H., Manerbino, A.R., Menzer, S., Coors, W.G., 2011. The design, fabrication, and evaluation of a ceramic counter-flow microchannel heat exchanger. Journal of Applied Thermal Engineering 31, 2004-2012.

Koyama, K., Asako, Y., 2010a. Experimental Investigation of Heat Transfer Characteristics on a Gas-to-Gas Parallel Flow Microchannel Heat Exchanger. The Open Transport Phenomena Journal 2, 1-8.

Koyama, K., Asako, Y., 2010b. Experimental investigation on heat transfer characteristics of a gas-to-gas counterflow microchannel heat exchanger. Experimental Heat Transfer 23, 130-143.

Meschke, F., Riebler, G., Hessel, V., Schürer, J., Baier, T., 2005. Hermetic Gas - tight Ceramic Microreactors. Chemical engineering \& technology 28, 465-473.

Mohammed, H.A., Gunnasegaran, P., Shuaib, N.H., 2011. Numerical simulation of heat transfer enhancement in wavy microchannel heat sink. International Communications in Heat and Mass Transfer 38, 63-68.

Tandogan, E., 2001. Optimierter Entwurf von Hochleistungswärmeübertragern. RuhrUniversität Bochum.

Webb, R.L., Kim, N.-H., 1994. Principles of Enhanced Heat Transfer. Taylor and Francis Group.
Wu, H.Y., Cheng, P., 2003. An experimental study of convective heat transfer in silicon microchannels with different surface conditions. International Journal of Heat and Mass Transfer 46, 2547-2556.

Wu, S., Li, Y., 2001. Exergy-economic criteria for evaluating heat exchanger performance. J. of Therm. Sci. 10, 218-222.

Yang, Y., Brandner, J.J., Morini, G.L., 2012a. Hydraulic and thermal design of a gas microchannel heat exchanger, 1st European Conference on Gas Micro Flows, Skiathos Island, Greece.

Yang, Y., Gerken, I., Brandner, J.J., Morini, G.L., 2012b. Design and experimental investigation of a gas-to-gas counter flow micro heat exchanger, European Conference of Microfluidics 2012, Heidelberg, Germany. 